\title{
Empirical "first-filter" test for the existence of buyer power in the Finnish food supply chain
}

\author{
Jyrki Niemi and Xing Liu \\ Luke Natural Resources Institute Finland, Economics and Society, Latokartanonkaari 9, FI-00790, Helsinki, \\ email: jyrki.niemi@luke.fi
}

\begin{abstract}
Buyer power and competition policy in food supply chains has emerged as an important economic issue and a highly sensitive item on the policy agenda around the world. In Finland, the increasing concentration of the distribution sector and processing industry has raised concern over the existence and gradual growth of buyer power in these sectors. The purpose of this paper is to investigate the possible existence of buyer power in the Finnish food supply chain. More specifically, we follow an approach used by Lloyd et al. (2009) to measure oligopsony power among the Finnish food industry and retailers against farmers. The results suggest that the spread between producer and retailer prices in Finland is not consistent with perfectly competitive behaviour, and might thus be caused, at least as a candidate amongst other factors, by the existence of oligopsony power in the Finnish food supply chain.
\end{abstract}

Key words: concentration, market power, VECM

\section{Introduction}

The food supply chain generally consists of three main sectors: the agricultural sector, the food processing industry and the distribution sectors (wholesale and retail) (Bukeviciute et al. 2009). Buyer power and competition policy in food supply chains has emerged as an important economic issue and a highly sensitive item on the policy agenda around the world (Digal and Ahmadi-Esfahani 2002, EC 2009). The Committee of Experts on Restrictive Business Practices defined buyer power as "a situation which exists when a firm or a group of firms, either because it has a dominant position as a purchaser of a product or service or because it has strategic or leverage advantages as a result of its size or other characteristics, is able to obtain from a supplier more favourable terms than those available to other buyers" (OECD 1981). The key concern is that growing buyer power may have the effect of considerably distorting both retail and producer competition, and eventually damaging economic welfare. Claims that large retailers and food companies are depressing farm prices because of their buyer power have been made in many countries around the world (Swinnen and Vandeplas 2009).

The food industry, and the retail sector in particular, have clearly consolidated through mergers and acquisitions as well as strategic alliances. As a result, retail buying is becoming increasingly concentrated (Dobson et al. 2003). This is particularly true in Finland. For example, the top three supermarkets share $88 \%$ of the grocery market, which is one of the highest figures in the world (FGTA 2014). The Finnish retail market has commonly been described as a near-duopoly (Kronqvist 2010). Meanwhile, several local food processing industries have a high level of concentration in Finland: For example, $70-80 \%$ of the processing meat market is shared by the top two suppliers, $50 \%$ of the liquid milk market is dominated by one supplier, and half of egg packaging is provided by one supplier. Increasing concentration in both the retailer sector and the processing sector raises concern over the existence and gradual growth of buyer power among retailers and processors. However, a large market share does not directly imply large market power (Baumol et al. 1982). Thus, the connection between market power and the level of concentration needs to be investigated empirically. Early efforts within the structure-conduct-performance (SCP) approach sought to econometrically relate measures of industrial concentration, such as the Herfindahl-Hirshman index ( $\mathrm{HHI}$ ), to indicators of profitability (e.g. the price-cost margin and Lerner index). However, while this simple approach may help to generate hypotheses and set the scene, its relative lack of theoretical foundations and static nature represent major weaknesses that prevent the identification of causal effects. Thus, in the Finnish context, while it is clear that the process of retailer and food industry concentration has accompanied growth in the marketing margin, this evolution does not provide evidence of non-competitive behaviour. For instance, Kuosmanen and Niemi (2009) argued that there are many plausible reasons for the declining pattern of producer price margins, such as an increased degree of processing, better food hygiene, differences in productivity growth across sectors, agricultural policy reforms, international trade and imperfect competition. 
Three approaches have generally been adopted in identifying and estimating oligopoly (or oligopsony) market power: structure-conduct-performance (SCP), new empirical industrial organization (NEIO) studies and price transmission. SCP studies have mainly used cross-sectional data to estimate the relationship between price-cost margins and concentration ratios to draw inferences about the presence of market power, while NEIO studies have generally tended to find some statistical evidence for market power by focusing on the determinants of the gap between prices and marginal costs (Wohlgenant 2001). The SCP approach has often been criticised for lacking a microeconomic foundation. NEIO is preferred to SCP, but is difficult to implement in empirical studies due to the high requirement for data. In comparison, price transmission models such as price-asymmetry models (von Cramon-Taubadel 1998, Götz et al. 2014) and the cointegration approach (Goodwin and Schoreder 1991, Lakuma 2014) are relatively easy to implement empirically. However, most applications "lack theory and cannot distinguish between collusion and perfectly competitive markets" (Digal and Ahmadi-Esfahani 2002).

Derived from the NEIO model with the help of empirical time series analysis, Lloyd et al. (2009) developed a test to measure oligopoly and oligopsony market power. The method provided a "first-filter" test for the possible existence of oligopoly /oligopsony market power in the UK food sector. In Finland, market power research in the food supply chain has been a new subject and the literature is very limited. Kuosmanen and Niemi (2009) assessed possible reasons for the widening gap between the retail and producer prices of food, where market power was listed as a clearly plausible explanation. However, the claim lacks empirical quantitative study to support it. Therefore, in this paper we attempt to use method of Lloyd et al. (2009) to offer a "first-filter" test in the Finnish food supply chain. By assuming that processing and retailing are one integrated sector can serve as a useful device for characterising how prices are transmitted in the food market, albeit in a simplified form. Furthermore, it forms the basis for determining the appropriate econometric approach and the interpretation of the key variables used to identify the existence of possible oligopsony power (Fabio et al. 2016) among downstream actors, namely food industries and retailers, against upstream farmers.

\section{Material and methods \\ Recent trends in Finnish food retailing}

The operating environment of the Finnish food economy radically changed in 1995 when Finland joined the European Union (EU). The commitment to the Common Agricultural Policy (CAP) of the EU led to unprecedented upheaval in the economic environment of the Finnish food chain. It was no longer possible to regulate the market price level of agricultural products through national border protection and export subsidies. The minimum prices for agricultural products guaranteed by the EU are much lower than the producer prices paid in Finland before EU membership, and the prices also vary more than before.

EU membership clearly reinforced the position of the retail sector in the food chain relative to the domestic raw material production and food industry. The retail sector is able to take advantage of the competition between domestic food companies and foreign ones. Structural changes in retail trade have directly influenced the market opportunities of food producers in four ways: through (1) concentration, (2) vertical integration, (3) discount stores and (4) private labels. As a result of the concentration in the retail trade sector, very large units, i.e. hypermarkets, have conquered market shares at the expense of smaller units (Koistinen and Vesala 2006). The concentration is reflected in both the rapid decrease in the number of retail outlets and in the market shares of the leading chains. From 1995 to 2013, the share of total sales accounted for by hypermarkets grew from 15\% to $28 \%$ and that of large supermarkets from $20 \%$ to as high as 35\% (FGTA 2014). At the beginning of 2014, the total number of retail groceries stores was 4066 , and $63 \%$ of the sales took place in the 882 largest stores.

In recent years, significant reorganisations have taken place among the largest chains. The competition for the market in groceries and daily consumer goods is increasingly clearly a case involving two main players. The market share of the S-group has increased rapidly over recent years. In 2014, the S-group managed to raise its market share again, reaching $45.7 \%$. The share of the K-group has been diminishing in the past few years. In 2014, the market share of the K-group reached $33.1 \%$. The grocery operations of both S-group and K-group companies have steadily increased in value in recent years.

The only international grocery store chain in Finland is the German discount giant Lidl, which has successfully spread on the Finnish market with its clear strategy of private label sales. In 2014, the market share of Lidl reached $7.6 \%$, having gained a $2.8 \%$ greater share in three years. The swift development of Lidl is proof of the popularity of discount stores, and retail chain's own brands. 


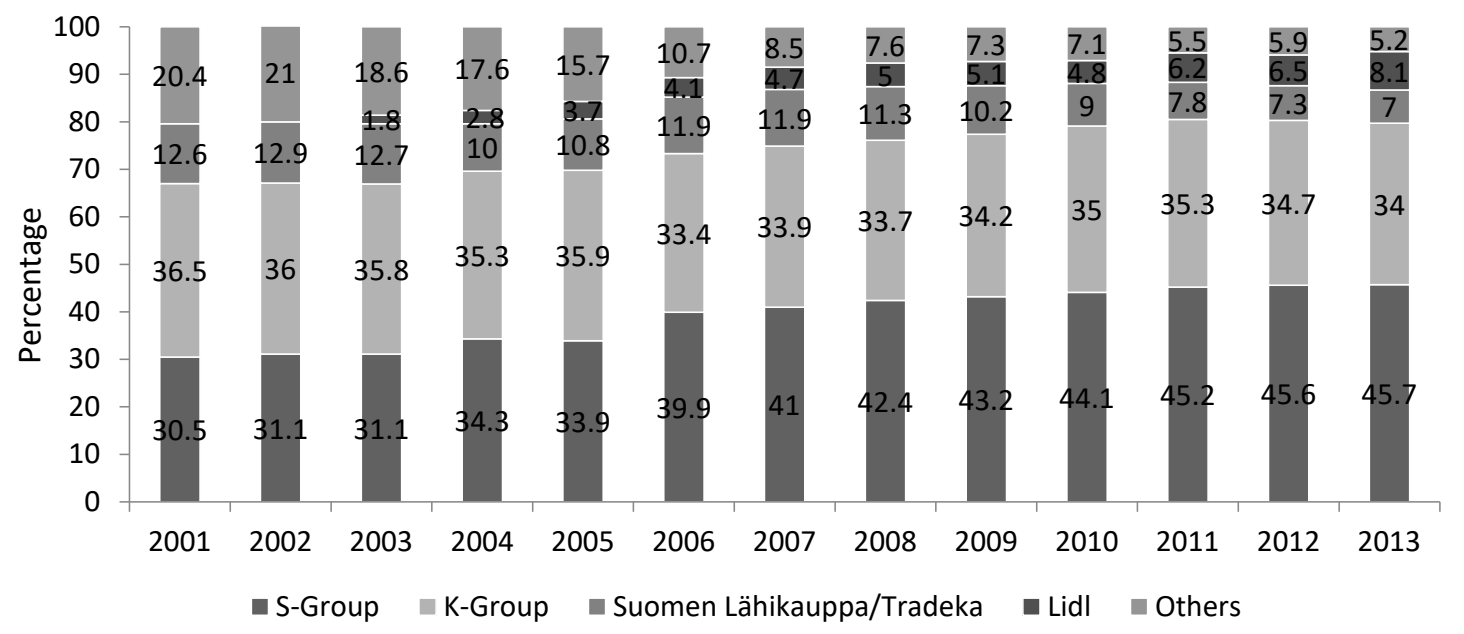

Fig. 1. Development of the market shares of Finnish grocery trade groups

The large food chains consist of independent retail operators who compete on the local markets, while the wholesale and purchasing operations within the chain are strongly concentrated. Large chains take advantage of their negotiation power in their supply contracts with food processing companies. In both leading chains, the share of concentrated purchases has risen to more than $80 \%$, leaving very little room for local purchases by the retail operators. Of local foods, the main ones to have gained access to shelves include some bakery products, fresh meat and fresh cheeses (Niemi and Ahlstedt 2015).

\section{Theoretical model and empirical implementation}

As mentioned in the introduction, this study utilizes a theoretical approach presented by McCorriston (2001) and Lloyd et al. (2009) exploiting the presence of exogenous shocks in order to identify the existence of buyer power in both upstream and downstream prices. In their theoretical framework, firms are assumed to produce a homogeneous product and pursue quantity-setting strategies. In addition, the model only allows us to detect the existence of market power, and not the degree of buyer power. The detection of buyer power simply depends on how the incidence of shocks affects both sets of prices. The model presented here follows the standard specification of equilibrium displacement models as in the framework of Gardner (1975), McCorriston (2001) and Lloyd et al. (2009), which are static models in which the retailing sectors or processing sectors buy raw products from farmers, convert them into finished products by performing various functions, and then sell the finished products to consumers. Thus, the inverse retail demand form is given by:

$$
R=h(Q, D)
$$

where $R$ is the retail price of the good, $Q$ is the food output the retailers sell to consumers and $D$ is an exogenous demand shifter (which represents the source of the demand shock affecting the retail sector). The input supply functions for the agricultural input $A$, in inverse form, are given by:

$$
P=l(A, S)
$$

where $P$ represents the price of $A$. The variable $S$ is the exogenous supply shifter in the farm supply equation. The food industry, for example a representative retail firm, uses the agricultural raw material to maximise its profits, given by the following function:

$$
\pi_{i}=\left[R(Q) Q_{i}-P(A) A_{i}-C_{i}\left(Q_{i}\right)\right]
$$

where $P(A) A_{i}$ represents the cost of all the agricultural inputs. In this theoretical framework, the firm uses agricultural inputs in combination with other variable inputs to produce a food product. To simplify the algebra in order to manage it, these non-agricultural inputs are subsumed into a single "other cost" input, which is $C_{i}$. In addition, constant returns to scale in distribution are assumed. Thus, the first order condition for profit maximisation gives 


$$
\frac{\partial \pi_{i}}{\partial Q_{i}}=\frac{\partial R}{\partial Q} \frac{\partial Q}{\partial Q_{i}} Q_{i}+R-\frac{\partial P}{\partial A} \frac{\partial A}{\partial Q_{i}} A_{i}-P \frac{\partial A_{i}}{\partial Q_{i}}-\frac{\partial C_{i}}{\partial Q_{i}}=0
$$

Here, we assume a fixed-proportions technology, i.e. $A_{i}=\rho Q_{i}$, where $\rho$ is the input-output coefficient. Then, (4) could be transformed to:

$$
\frac{\partial R}{\partial Q} \frac{\partial Q}{\partial Q_{i}} Q_{i}+R=\frac{\partial P}{\partial A} \frac{\partial A}{\partial A_{i}} \rho A_{i}+P \rho+\frac{\partial C_{i}}{\partial Q_{i}}
$$

Empirically, the linear and the log-linear forms are among the most common in estimating the demand and supply function, as the demand curve could be expressed by a general Box-Cox transformation given by $\left(Q^{\xi}-1\right) / \xi=h-a\left(R^{\xi}-1 / \xi\right) ;$ when $\xi=1$ we have the linear demand case (McCorriston 2001). Thus, using linear functional forms for both the demand and supply function with exogenous demand shifter $D$, we get:

$$
\begin{gathered}
Q=h-a R+b D \\
P=l+k A
\end{gathered}
$$

and $A$, representing the supply input, could be determined by the food output to the retailers $Q$ and the exogenously determined supply shifter $S$ :

$$
A=Q+S
$$

Setting up $\rho=1$ in order to obtain the explicit solution, we could rewrite equation (4) as:

$$
R=k \frac{\partial Q}{\partial Q_{i}} Q_{i}+\frac{1}{a} \frac{\partial Q}{\partial Q_{i}} Q_{i}+P+\frac{\partial C_{i}}{\partial Q_{i}}
$$

According to Sexton and Lavoie (2001), "A key feature of any model of imperfect competition is the manner in which rival firms respond or react to one another." Empirically, most authors of static structural market models of imperfect competition in agriculture have used the paradigm of conjectural variations (Holloway 1991, McCorriston et al. 2001, Lloyd et al. 2009). Aggregate conjecture elasticity can be described as $\theta=\left(\sum_{i}\left[\frac{\partial Q}{\partial Q_{i}}\right]\left[\frac{Q_{i}}{Q}\right]\right) / n$ Here, $\theta_{i}=\partial Q / \partial Q_{i}$ is the conjectural variation parameter for firm $i$. Assuming $n$ equal-sized firms with an identical cost structure, as is common with industrial organisation models of this type, it is assumed that the conjectural variation parameters are identical across all firms (Cowling and Waterson 1976). Thus, we could rewrite (7) to be the following:

$$
R=k \theta Q+\frac{\theta}{a} Q+P+M
$$

where $M$ is a composite variable that represents all other costs that affect the retail-farm price margin. More generally, $\theta$ may be thought of as an index of buyer power. If $\theta=0$, we have competitive behaviour, and if $\theta=1$, we have collusive behaviour. Therefore, if there is no buyer power in a market, equation (8) could be reduced to:

$$
R=P+M
$$

Consequently, the spread between the retailing price and producer price in a perfectly competitive industry is solely attributed to marketing costs under competitive conditions. In this case, the exogenous shifters from both the demand side and supply side have no impact on determining the spread. Thus, the exogenous shifter cannot determine the difference between the prices at each stage of the food chain.

If buyer power exists, the spread between retail and producer supply prices behaves differently, since price setting by the sector with buyer power will be reflected in the mark down that the firms can earn, and so affects the spread. Hence, where buyer power exists, market shocks have a differential impact at each stage in the marketing chain and thus determine the behaviour of the spread between prices at different vertical levels, in addition to 
marketing costs. In effect, shocks to the underlying supply and demand functions are mediated through buyer power parameters and thus give rise to predictable effects on the spread. In the absence of buyer power, the effect of shocks is common at all vertical market levels, so that the spread is simply determined by marketing costs.

The theoretical framework delivers an equation for the determination of the price spread in which the impact of these shocks appears with a definite sign in the presence of oligopsony power. Noticeably, we assume that processing, wholesaling and retailing stages in Finland are one integrated sector. This provides the theoretical basis for a simple empirical test of the presence or otherwise of perfect competition. Writing the margin equation in an unrestricted form (i.e. in terms of prices), an empirical testable equation given by Lloyd et al. (2009) is the following:

$$
R=\beta_{0}+\beta_{1} P+\beta_{2} D+\beta_{3} S+\beta_{4} M
$$

where $R$ is the retail price and $P$ is the producer price of the good under consideration, $M$ is a composite variable that represents all other costs that affect the retail-farm price margin, $D$ is a general demand shifter, and $S$ is the exogenous shifter in the farm supply equation. The expected signs for the coefficients are $b_{1}>0, b_{4}>0$, irrespective of the degree of retail competition. The test of perfect competition can be achieved by testing whether the remaining variables in equation (10) are significant. More precisely, if $B_{2}=B_{3}=0$, the perfect competition condition is fulfilled; otherwise, imperfect competition exists in the market. Furthermore, with constant elasticity functional forms, if oligopsony power is exercised, the margin between the retail price and producer price can be caused by either an increasing shock to the demand shifter or decreasing shock to the supply shifter. As a result, either the sign of the demand shifter should turn positive or the sign of the supply shifter should turn negative, i.e. $B_{2}>$ 0 or $B_{3}<0$ would be significant in equation (10).

Empirically, we assume that the data may be approximated by a VAR (p) model as follows:

$$
X_{t}=\psi_{1} X_{t-1}+\cdots+\psi_{2} X_{t-2}+\cdots+\psi_{m} X_{t-m}+\Phi Z_{t}+v_{t}
$$

where $X_{t}$ is a $(k \times 1)$ vector of jointly determined $I(1)$ variables, $Z_{t}$ is a $(d \times 1)$ vector of deterministic terms (constants, trends and centred seasonals), and each i $\Phi(i=1, K, p)$ and each $\psi(I=1, \ldots, m) \Phi$ is a $(k \times k)$ and $(k \times d)$ matrix of coefficients to be estimated using a $(t=1, \ldots T)$ sample of the data. $v_{t}$ is a $(k \times 1)$ vector of $n . i . d$. disturbances with zero mean and a non-diagonal covariance matrix, $\Sigma$.

The presence of a price transmission relationship between the retailer and producer is indicated by the detection of cointegration among the variables in $x_{t}$. Rearranging (11) into its error correction form,

$$
\Delta X_{t}=\alpha \beta^{\prime} X_{t-m}+\sum \Gamma_{i} \Delta X_{t-1}+\Phi D_{t}+v_{t}
$$

we test for cointegration using Johansen's (1988) maximum likelihood procedure in which attention focuses on the $(k \times r)$ matrix of co-integrating vectors, comprising 6 , that quantify the 'long-term' (or equilibrium) relationships between the variables in the system and the $(k \times r)$ matrix of error correction coefficients, $\alpha$, the elements of which load deviations from equilibrium (i.e. $B>x_{t-m}$ ) into $\Delta x_{t}$, for correction. The $\Gamma_{i}$ coefficients in (12) estimate the shortterm effect of shocks on $\Delta x_{t^{\prime}}$ and thereby allow the short- and long-term responses to differ.

When a single cointegrating relationship is detected between retail and producer prices, formal testing of the significance of the supply and demands shocks is undertaken to investigate whether buyer power is present. If the vertical market for a product is perfectly competitive, retail and producer prices may be expected to form a cointegrated relationship with at most marketing costs. If buying power is exerted in Finnish food supply chain, the supply and demand shifters also enter the pricing relationship. This then gives rise to a null hypothesis of perfect competition, which can be empirically evaluated by a standard likelihood ratio test of the exclusion restrictions on the shifters in the cointegrating relationship.

In addition, given that the theoretical model signs the parameters in the pricing relationship (10), we can offer some additional evidence on the possible rejection of perfect competition by comparing the estimated signs of the shifters in the cointegrating relationship with that predicted by the theoretical model. 


\section{Data}

We apply the test method of Lloyd et al. (2009) to assess whether we can reject perfect competition in Finnish food supply chain using the best available market-level data on food price indices at retail $(R)$ and producer $(P)$ levels. In detail, $(P)$ is the producer price index for food products exclusive of taxes for the domestic market before the gate of factories. $(R)$ is the retailer price index for food products exclusive of taxes for the domestic market. (M) measures marketing costs, which are not available. Thus, given the importance of labour costs in food retailing, especially in Finland, we use an index of real average earnings in the Finnish retailing sector to proxy for these costs. The supply shifter $(S)$ is the exogenous shifter in the behaviour of the farm supply equation. To incorporate the impact of farm-level production costs, we use a real price index of all goods and services purchased on Finnish farms as representative of (S). D is a general demand shifter representing demand-side shocks. We use a general consumer price index affecting the retailing sector as a whole to represent $D$. All the indices were obtained from Statistics Finland between January 1995 and September 2013, with 228 monthly observations sampled altogether. The price indices are plotted in Figure 2, and the statistics of these series are summarised in Table 1.

Table 1. Descriptive statistics for the index series

\begin{tabular}{lccccc}
\hline Description & $\mathrm{R}$ & $\mathrm{P}$ & $\mathrm{DS}$ & $\mathrm{SS}$ & $\mathrm{M}$ _SA \\
\hline Mean & 112.1 & 94.5 & 115.9 & 121.2 & 187.2 \\
Median & 109.0 & 91.1 & 114.1 & 113.3 & 183.4 \\
Standard Deviation & 13.2 & 8.9 & 11.1 & 21.0 & 51.9 \\
Skewness & 0.7 & 1.1 & 0.3 & 0.8 & 0.1 \\
Kurtosis & 2.5 & 3.2 & 2.0 & 2.2 & 1.7 \\
Observation & 228 & 228 & 228 & 228 & 228 \\
\hline
\end{tabular}

All the indices are in nominal terms.

Seen from Figure 2, the price index $(P)$ representing the producer price remained very much at the same level within the sample year, while all other index series have shown a clearly increasing trend over the years. The marketing cost labelled by $\mathrm{M}$ especially shows a strong seasonal effect due to the allowance paid for the summer holiday. In order to demolish the seasonal effect, we use the Census X11 methods to adjust the original data and reproduce data labelled as M_SA. The Census X11 methods (multiplicative and additive), provided by Eviews 7.1, are the standard methods used by the U.S. Bureau of Census to seasonally adjust publicly released data. The spread between the retail price and producer indices is presented in Figure 3. Clearly, this gradually widening spread between retail price and producer price indices over time became more frequent after 2008 . Growth in the price spread is not in itself indicative of buyer power of retailing sector, as marketing costs such as labour costs may be the cause for this phenomenon (Lloyd et al. 2009). Nevertheless, it is a complementary indicator of the existence of buyer power. Thus, further investigation into the existence of buyer power, including related factors such as marketing costs, should be carefully carried out.

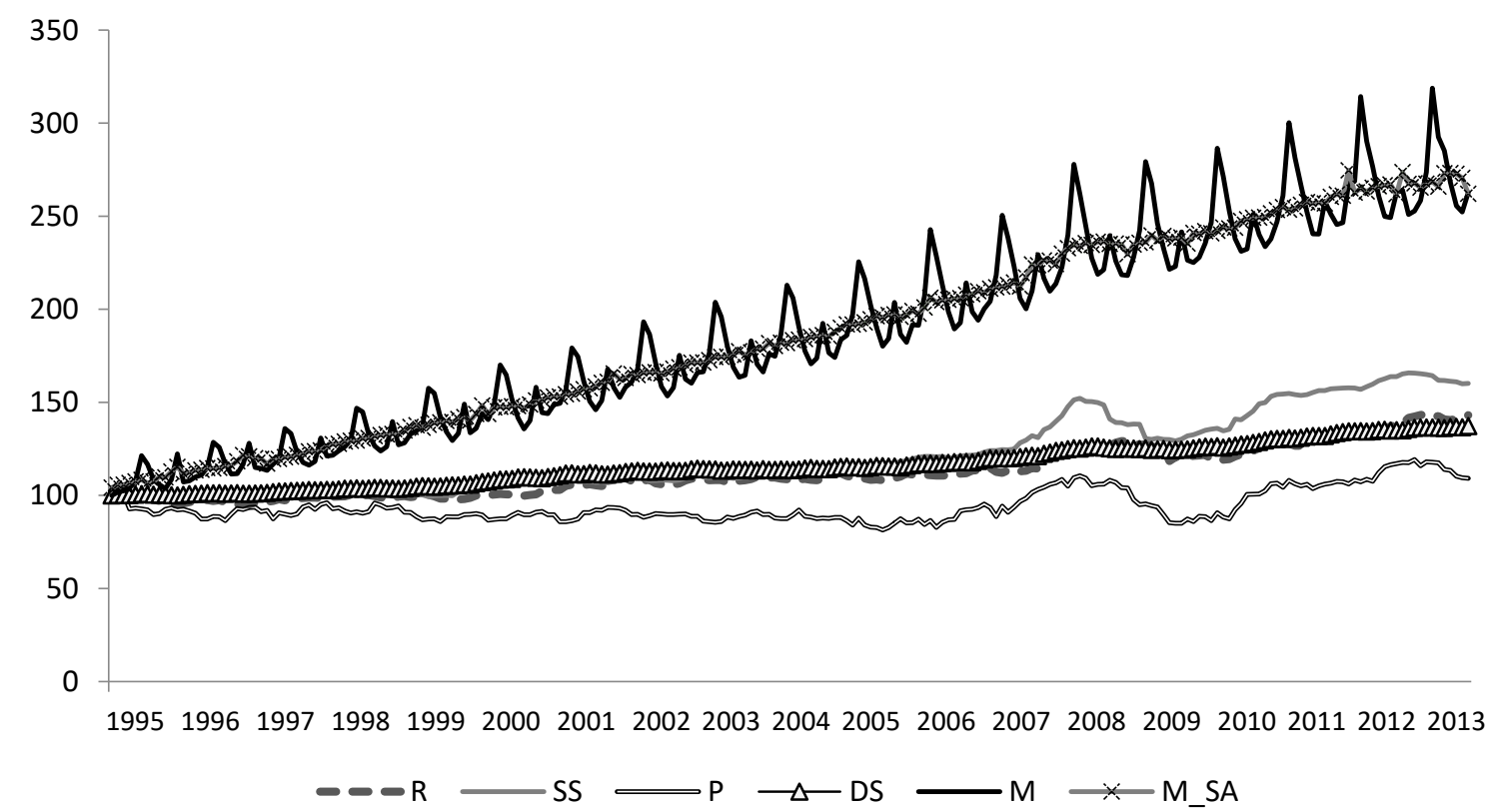

Fig. 2. Food price indices at retail (R) and producer (P) levels between 1995 and 2013 


\section{Results}

To decide whether VAR(p) or VECM was an appropriate model for our analysis, we utilized the logarithmic form of the price series drafted in Figure 1, labelled as LogR, LogP, LogDS, LogSS, and LogM, respectively, in Table 2. We first examined the stationarity properties of the univariate time series of individual price series. The series is integrated of order $d$ (denoted I(d)) if it attains stationarity after differencing $d$ times. If the series is I(1), it is deemed to have a unit root. Stationarity of the price processes was tested using the Augmented Dickey-Fuller (ADF) test (1976) and complementary Kwiatkowski-Phillips-Schmidt-Shin (KPSS) test (Kwiatkowski et al. 1992).

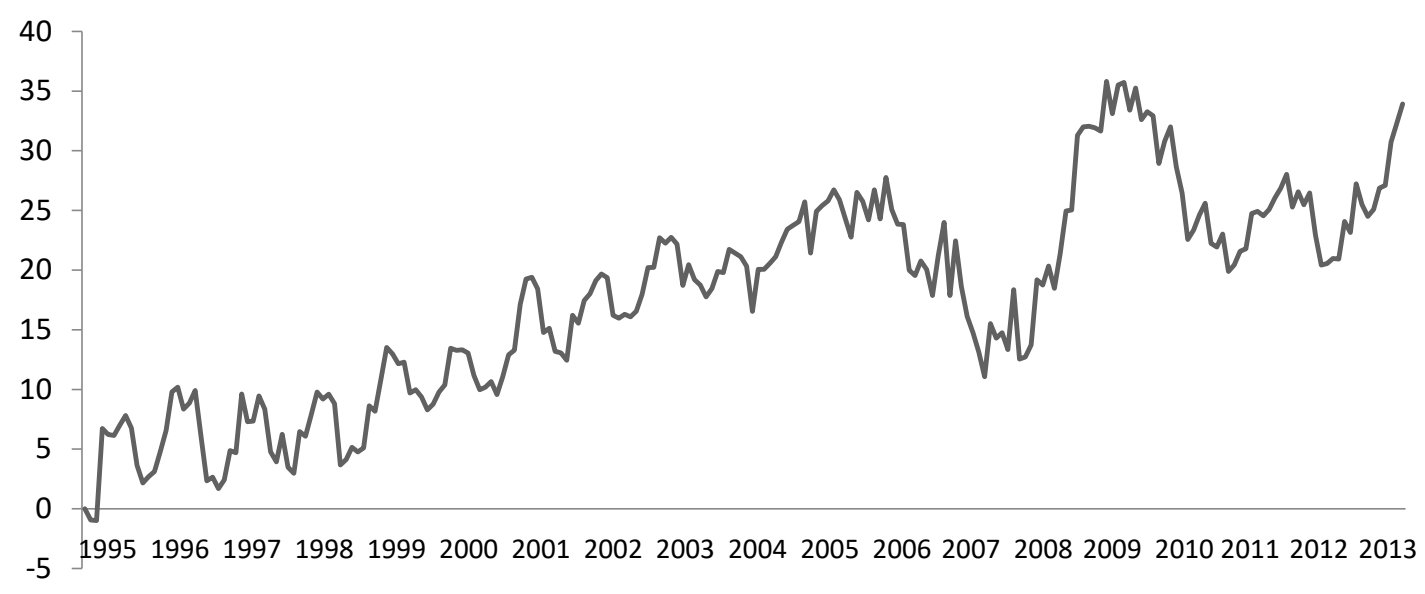

Fig. 3. Spread between the retail price index and producer price index between 1995-2013

Inspection of Figure 1 suggests that the series follows an increasing trend that characterizes the random walk I(1) model. Thus, we considered performing the unit root tests with two different restricted structures: with an intercept and with an intercept and a trend. The results of the unit root tests in level form are reported in Table 2. All the tests indicate that all of the index series restricted on the intercept were non-stationary, and further tests on the first difference show stationarity, which suggests that the index series were I(1) with either an intercept or with an intercept and a trend. Given that the data were all integrated in the first order, we next analysed the price transmission between the retail price and producer supply price using the VECM model defined by equation (12). Thus, the second step of our analysis was to test the cointegration relationship among the index series.

Table 2. Unit root test result of individual price indices

\begin{tabular}{|c|c|c|c|c|c|c|}
\hline Test & $\log R$ & LogP & LogDS & LogSS & LogM & Critical values \\
\hline $\begin{array}{c}\text { ADF } \\
\text { (intercept and trend } \\
\text { included) }\end{array}$ & -2.85 & -1.55 & -2.11 & -2.70 & -2.58 & $\begin{array}{l}-3.44 * * \\
-4.01 * * *\end{array}$ \\
\hline $\begin{array}{c}\text { ADF } \\
\text { (intercept included) }\end{array}$ & 1.04 & -2.66 & 0.30 & -0.18 & -0.21 & $\begin{array}{l}-2.88^{* *} \\
-3.47^{* * *}\end{array}$ \\
\hline $\begin{array}{c}\text { KPSS } \\
\text { (intercept and trend } \\
\text { included) }\end{array}$ & $\begin{array}{l}0.27 \\
* * *\end{array}$ & $\begin{array}{l}0.28 \\
* * *\end{array}$ & $\begin{array}{l}0.46 \\
* * *\end{array}$ & $\begin{array}{l}0.34 \\
* * *\end{array}$ & $\begin{array}{l}0.42 \\
* * *\end{array}$ & $\begin{array}{l}0.15 * * \\
0.22 * * *\end{array}$ \\
\hline $\begin{array}{c}\text { KPSS } \\
\text { (intercept included) }\end{array}$ & $\begin{array}{l}1.88 \\
* * *\end{array}$ & $\begin{array}{l}0.88 \\
* * *\end{array}$ & $\begin{array}{l}1.96 \\
* * *\end{array}$ & $\begin{array}{l}1.85 \\
* * *\end{array}$ & $\begin{array}{l}1.99 \\
* * *\end{array}$ & $\begin{array}{l}0.46 * * \\
0.74 * * *\end{array}$ \\
\hline
\end{tabular}

$A D F=$ the Augmented Dickey-Fuller test. Test statistics are according to MacKinnon (1996) critical values for rejection of the hypothesis of a unit root. KPSS is the $\eta$-test of Kwiatkowski et al. (1992). Asterisks $(* *)$ and $(* * *)$ denote the significance level at $5 \%$ and $1 \%$, respectively.

The result of the Johansen cointegration test is presented in Table 3. The Akaike information criterion was used to determine the optimal order of lags ( 3 lags for each series). Both the trace statistics and the maximum eigenvalue indicate that a single cointegrating vector $(r=1)$ is found significant, whether or not the linear trend restriction is included. Furthermore, under sequential testing, the first rejection failure occurs while using the model with a trend, and we thus accept the model with a trend as appropriate. We further checked the cointegrating residuals for autocorrelation and the trending test, and the results appear to be satisfactory. 
Table 3. Test for cointegration among LogR, LogP, LogDS, LogS and LogM index series

\begin{tabular}{|c|c|c|c|c|}
\hline \multicolumn{5}{|c|}{ (i) Constant included } \\
\hline Hypothesized No. of CEs & Max. Eigenvalue & $5 \% \max$ & Trace statistic & $5 \%$ trace \\
\hline$r=0$ & $52.71 * *$ & 33.88 & $98.08 * *$ & 69.82 \\
\hline$r=1$ & 26.26 & 27.58 & 45.37 & 47.86 \\
\hline$r=2$ & 10.66 & 21.13 & 19.11 & 29.80 \\
\hline$r=3$ & 6.77 & 14.26 & 8.45 & 15.49 \\
\hline$r=4$ & 1.68 & 3.84 & 1.67 & 3.84 \\
\hline \multicolumn{5}{|c|}{ (ii) Constant and linear trend included } \\
\hline Hypothesized No. of CEs & Max. Eigenvalue & $5 \% \max$ & Trace statistic & $5 \%$ trace \\
\hline$r=0$ & $57.85^{* *}$ & 38.33 & $88.80 * *$ & 69.82 \\
\hline$r=1$ & 26.45 & 32.12 & 63.88 & 47.86 \\
\hline$r=2$ & 19.26 & 25.82 & 42.92 & 29.80 \\
\hline$r=3$ & 8.39 & 19.38 & 25.87 & 15.49 \\
\hline$r=5$ & 2.88 & 12.52 & 12.52 & 3.84 \\
\hline
\end{tabular}

Critical values based on MacKinnon-Haug-Michelis (1999); ** = rejection of the hypothesis at the $5 \%$ level

Next, Table 4 reports the parameters of the cointegrating vectors normalised on the retail price index obtained from equation (12) along with results from the misspecification tests. The results show that $B_{1}>0$, which is in accordance with theoretical model 1 . However, it is noteworthy that the $B_{4}$ parameter of the coefficient of $M$ representing the marketing cost shows a negative sign but is not statistically significant. This implies that labour costs alone may not provide the best proxy as a general marketing cost variable. In addition, the positive sign of the demand shift $B_{2}>0$ and negative sign of the supply shift $B_{3}<0$ indicate that buyer power exists, and the signs are in line with the theoretical model presented in (10), even though $B_{3}$ is not statistically significant. At the end of Table 4, we add the misspecification test values, including the Autocorrelation LM test and White heteroscedasticity test, recommended by Juselius $(1998,2006)$ together with others (Ben-Kaabia et al. 2005). The results of residual autocorrelation suggest that there is no remaining autocorrelation and the White heteroscedasticity test indicates that the null of homoscedasticity cannot be rejected.

Table 4. Estimated cointegrating vectors (normalised on the retail price index)

\begin{tabular}{|c|c|c|}
\hline Index proxies & Parameters & Values \\
\hline Producer price index (LogP) & $\beta_{1}$ & $0.19 * * *(0.05)$ \\
\hline Demand shifter index (LogDS) & $\beta_{2}$ & $0.66 * * *(0.19)$ \\
\hline Supply shifter index (LogSS) & $\beta_{3}$ & $-0.08(0.07)$ \\
\hline Marketing cost (LogM) & $\beta_{4}$ & $-0.16(0.08)$ \\
\hline Trend $(\mathrm{T})$ & & $0.0012 * *(0.0004)$ \\
\hline R-square & 0.32 & \\
\hline Serial correlation LM Test $(\operatorname{lag}=10)^{\mathrm{a}}$ & & $31.40[0.18]$ \\
\hline White heteroscedasticity $(1)^{\mathrm{b}}$ & & $517.00[0.13]$ \\
\hline
\end{tabular}

In order to obtain a more precise statistical significance of coefficients $S$ and $D$, we further performed a set of likelihood ratio tests. The results are displayed in Table 5, and the null hypothesis of perfect competition $\left(B_{2}=B_{3}=0\right)$ between producer and retailing prices is clearly rejected. Although $B_{3}=0$ alone cannot be rejected, it is correctly signed according to the theoretical model (see Table 4). Therefore, the results suggest overall that the spread between producer and retailer prices is not consistent with perfectly competitive behaviour and thus might be caused, at least as a candidate amongst other factors, by the existence of oligopsony power in Finnish food retailing. 


\begin{tabular}{ll}
\multicolumn{2}{l}{ Table 5. Test results for competition } \\
\hline Hypotheses & Values \\
\hline$H_{0}: \beta_{2}=0$ & $8.24[0.002]$ \\
$H_{0}: \beta_{3}=0$ & $0.96[0.33]$ \\
$H_{0}: \beta_{2}=\beta_{3}=0$ & $8.72[0.00]$ \\
\hline
\end{tabular}

Figures in brackets are $p$-values.

\section{Discussion}

In this paper, we have applied the test method by Lloyd et al. (2009) to test the presence of buyer power in vertically related Finnish food supply chain. The approach is straightforward and transparent, and delivers a statistical test derived from a theoretically consistent basis. Furthermore, the test demands relatively little in terms of data and is implemented using standard techniques of modern time-series analysis.

The empirical result suggests that the hypothesis of perfect competition can be rejected, implying that the Finnish market is characterised by buyer power according to the measure of Lloyd et al. (2009). Of course, the result cannot be interpreted as providing conclusive evidence for the use of buyer power in Finnish food retailing and processing. Clearly, econometric tests of this sort have limitations. The data are subject to measurement problems, particularly regarding the quality of proxies that are available to account for changes in sector-specific marketing costs (demand and supply shocks), which are not to be taken lightly. Given this complexity, general conclusions regarding the functioning of the food supply chain have to be drawn with caution. It should also be stressed that the test does not allow the degree or economic significance of market power to be measured, but merely indicates whether it exists. However, the method proposed by Lloyd et al. (2009) is both familiar to applied economists and readily implemented, and delivers a 'first-filter' test that when used in combination with other evidential indicators can contribute to uncovering the existence of buyer power in the vertical food chain. This better understanding of the functioning of the food supply chain will also contribute to a more informed debate on policy proposals with stakeholders.

\section{Acknowledgement}

This research was funded by Ministry of Agriculture and Forestry (Project: Ruokamarkkinoiden toimivuus ja elintarvikemarkkinoiden hinnanmuodostus).

\section{References}

Ben-Kaabia M., Gil, J.M. \& Ameru, M. 2005. Vertical integration and non-linear price adjustments: The Spanish poultry sector. Agribusiness 21: 253-271.

Baumol, W.J., Panzar J.C. \& Willig R.D. 1982. Contestable markets and the theory of industry structure. Harcourt Brace Jovanovich, Inc, New York. 510p.

Bukeviciute, L., Dierx A. \& Ilzkovitz, F. 2009. The functioning of the food supply chain and its effect on food prices in the European Union. Occasional Papers on Economic and Financial Affairs. http://ec.europa.eu/economy_finance/publications. doi: 10.2765/43477.

Digal, L. \& Ahmadi-Esfahani, F. 2002. Market power analysis in the retail food industry: a survey of methods. Australian Journal of Agricultural and Resource Economics 46: 559-584.

Dobson, P., Waterson, M. \& Davies, S. 2003. The patterns and implications of increasing concentration in European food retailing. Journal of Agricultural Economics 54: 111-125.

EC 2009. Competition in the food supply chain. Commission staff working document, Competition in the food supply chain, (28 October, 2009). http://ec.europa.eu/economy_finance/publications/publication 16065_en.pdf.

Fabio, A.M., Roberto, F. \& Pietro, P. 2016. The existence of buyer power in the Italian fresh milk supply chain. British Food Journal 118: $70-82$

FGTA 2014. Finnish Grocery Trade 2014. http://www.pty.fi/fileadmin/user_upload/tiedostot/Julkaisut/Vuosijulkaisut/EN_2014_ vuosijulkaisu.pdf.

Gardner, B. 1975. The farm-retail price spread in a competitive food industry. American Journal of Agricultural Economics 57: 399-409.

Goodwin, B.K. \& Schroeder, T.C. 1991. Cointegration tests and spatial price linkages in regional cattle markets. American Journal of Agricultural Economics 73: 452-464. 
Götz, L., von Cramon-Taubadel, S. \& Kachel, Y. 2014. Vertical Price Transmission in the International Fresh Fruitand Vegetable Supply Chain: Israeli Grapefruit Exports to the EU after Export Liberalisation. Quarterly Journal of International Agriculture 53: 99-120.

Holloway, G.J. 1991. The farm-retail price spread in an imperfectly competitive food industry. American Journal of Agricultural Economics 73: 979-989.

Juselius, K. 1998. Changing monetary transmission mechanisms within the EU. Empirical Economics 23: 455-481.

Juselius, K. 2006. The Cointegrated VAR Approach: Methodology and Applications. Advanced Texts in Econometrics. Oxford, Oxford University Press. $457 \mathrm{p}$

Koistinen, K. \& Vesala, T. 2006. Päivittäistavarakaupan rakennemuutos Suomen keskeisillä kaupunkiseuduilla 1995-2003 (Structural change within grocery retailing in prominent Finnish urban areas 1995-2003). National Consumer Research Centre, publications 6:2006. Helsinki. 79 p.

Kronqvist, T. 2010. Consumer-Owned Retail Co-operative in Duopoly with Horizontally Differentiated Goods: A Finnish experience. (PhD. Thesis). Department of Economics, Helsinki School of Economics. 117 p.

Kuosmanen, T. \& Niemi, J. 2009. What explains the widening gap between the retail and producer prices of food? Journal of Agricultural and Food Science 18: 317-331.

Kwiatkowski, D., Phillips, P.C.B., Schimidt, P. \& Shin, Y. 1992. Testing the null hypothesis of stationarity against the alternative of a unit root. How sure are we that economic time series have a unit root? Journal of Econometrics 54: 159-178.

Lakuma, C.E.P. 2013. Testing cointegration and market power in the American crude oil industry. International Journal of Economics and Finance 5 (12). doi:10.5539/ijef.v5n12p163.

Lloyd, T., McCorriston, S., Morgan, W., Rayner, A. \& Weldegebriel, H. 2009. Buyer power in U.K. food retailing: A 'first-pass' test. Journal of Agricultural \& Food Industrial Organization 7: 1-37.

McCorriston, S., Morgan, C.W. \& Rayner, A.J. 2001. Price transmission: the interaction between market power and returns to scale. European Review of Agricultural Economics 28: 143-159.

Niemi, J. \& Ahlstedt, J. 2015. Finnish agriculture and rural industries 2015. Natural resources and bioeconomy studies 26/2015, Natural Resources Institute Finland, Helsinki. 90 p.

OECD 1981. Buying power: The exercise of market power by dominant buyers. Report of Committee of Experts on Restrictive Practices. OECD, Paris. 178 p.

Sexton, R. \& Lavoie, N. 2001. Food processing and distribution: An industrial organization approach. In: Gardner, B. \& Rausser, G. (eds.). Handbook of agricultural economics Vol. 1B. Amsterdam, North Holland. p. 864-932.

Swinnen, J. \& Vandeplas, A. 2010. Market power and rents in global supply chains. Agricultural Economics 41 (s1): 109-120.

von Cramon-Taubadel, S. 1998. Estimating asymmetric price transmission with the error correction representation: An Application to the German Pork Mark. European Review of Agricultural Economics 25: 1-18.

Wohlgenant, M. 2001. Marketing margins: Empirical analysis. In: Gardner B. \& Rausser G. (eds.). Handbook of agricultural economics, Vol. 1B. Amsterdam, North Holland. p. 933-970. 